\title{
TCDD mediates inhibition of p53 and activation of ER $\alpha$ signaling in MCF-7 cells at moderate hypoxic conditions
}

\author{
ANJA SEIFERT ${ }^{1}$, HELGE TAUBERT ${ }^{2}$, SABINE HOMBACH-KLONISCH ${ }^{3}$, \\ BERND FISCHER $^{1}$ and ANNE NAVARRETE SANTOS ${ }^{1}$ \\ ${ }^{1}$ Department of Anatomy and Cell Biology, ${ }^{2}$ Institute of Pathology, Martin Luther University Faculty of Medicine, \\ Halle, Germany; ${ }^{3}$ Department of Anatomy and Cell Science, University of Manitoba, Winnipeg, Canada
}

Received February 18, 2009; Accepted April 22, 2009

DOI: 10.3892/ijo_00000354

\begin{abstract}
TCDD (2,3,7,8-tetrachlorodibenzo-p-dioxin) is known to promote cancer initiation and progression and accumulates in mammary fat tissue. Effects of TCDD are mediated by the aryl hydrocarbon receptor (AhR). Physiological conditions of moderate hypoxia in breast cancer also activate another transcription factor, hypoxia-inducible factor- 1 alpha $(\mathrm{HIF}-1 \alpha)$. In addition, the transcription factors p53 and the estrogen receptor alpha $(\mathrm{ER} \alpha)$ are important key players in breast cancer progression. Here, human breast cancer cells cultured under mild hypoxic conditions were exposed to TCDD and analyzed for regulation of p53 signaling and $\mathrm{ER} \alpha$ transactivation. Simultaneous exposure to TCDD and hypoxia resulted in a moderate but reproducible inhibition of p53 expression. Both the direct activation of the ER $\alpha$ and the transcriptional regulation of $\mathrm{Hdm} 2$ mediated this inhibition. As consequence the p53-mediated target gene expression (Dusp5) was reduced. Silencing of Dusp5 by simultaneous exposure of TCDD and hypoxia or by RNAi led to increased phosphorylation of ERK1/2. This increase resulted in transactivation of $\mathrm{ER} \alpha$ and induction of $\mathrm{ER} \alpha$-mediated transcription of Hdm2 and SOCS3. Specificity of ER $\alpha$-transactivation by ERK1/2 was confirmed by treatment with MAPKK-inhibitor
\end{abstract}

Correspondence to: Dr Anja Seifert, Department of Pharmacology and Toxicology, Otto-von-Guericke University, Leipziger Strasse 44, D-39120 Magdeburg, Germany

E-mail: seifert-anja-halle@gmx.de

Abbreviations: TCDD, 2,3,7,8-tetrachlorodibenzo-p-dioxin; AhR, aryl hydrocarbon receptor; HIF-1 $\alpha$, hypoxia-inducible factor-1 alpha; ER $\alpha$, estrogen receptor alpha; ANF, alpha-naphthoflavone; ARNT, aryl hydrocarbon receptor nuclear translocator; VEGF, vascular endothelial growth factor; Cyp1A1, cytochrome $1 \mathrm{~A} 1$; Hdm2, human homologue of mouse double minute 2; ERK1/2, extracellular signal-regulated kinase1/2; Dusp5, dual specific phosphatase 5; SOCS3, suppressor of cytokine signaling 3; PD98059, inhibitor of MEK1/2

Key words: ER $\alpha$, p53, MCF-7, AhR, HIF-1 $\alpha, \mathrm{Hdm} 2$
PD98059. The combination of inhibition of functional p53 protein and induction of ER $\alpha$ signaling could serve as a model for the operational sequence of TCDD effects to prevent cell death and promote breast tumor progression.

\section{Introduction}

The MCF-7 cell line, derived from a pleural effusion of a patient with metastatic breast cancer, is the most common cellular model for estrogen-dependent breast cancer and has been extensively used to analyze the regulation of gene expression by estrogen and the AhR-ER $\alpha$ cross-talk. Estrogen induces tissue-specific responses through binding to the estrogen receptor (ER $\alpha$ and ERß). Phosphorylation in the AF1 domain by MAPK is able to transactivate the ER independent of its ligand (1). An inhibitory cross-talk between ER and AhR signaling has been described through various mechanism (2). For example, an increased proteasomal degradation of the ER $\alpha$ after AhR activation was described (3). The most potent ligand of the AhR is 2,3,7,8-tetrachlorodibenzo-para-dioxin (TCDD). TCDD is highly persistent in the environment and a prototypical compound within a family of toxic chemicals that include polycyclic and halogenated aromatic hydrocarbons (4) that causes a broad spectrum of biochemical and toxic effects. The environmental pollutant TCDD promotes the development of various tumors in mice, rats and guinea pigs (5). Lipophilic TCDD accumulates in adipose tissue (6). Furthermore, in the Seveso women's health study (7) the incidence of breast cancer, among others, was significantly increased and correlated positively with higher serum TCDD levels.

The aryl hydrocarbon receptor (AhR) and the hypoxiainducible factor- $1 \alpha$ (HIF- $1 \alpha)$ are members of the basic helix-loop-helix (bHLH)/Per-ARNT-SIM (PAS) family of transcription factors and mediate the response to various environmental stimuli (8). HIF-1 $\alpha$ is activated by hypoxia. An oxygen concentration of 8.55 and $3.68 \%$ was reported in breast carcinoma (stage T1B to T4), respectively (9). Both transcription factors, AhR and HIF-1 $\alpha$, translocate into the nucleus and heterodimerize with the aryl hydrocarbon receptor nuclear translocator (ARNT). The active AhR-ARNT complex binds to a promoter region containing xenobiotic response elements (XRE) inducing AhR target genes such as Cyp1 
family members and several drug-metabolizing enzymes (10). The activated HIF-1 $\alpha /$ ARNT complex binds to the hypoxia response element (HRE) inducing target genes such as vascular endothelial growth factor (VEGF) and erythropoietin (11).

Several studies have shown Hdm2-dependent interactions between HIF-1 $\alpha$ and p53. Two p53 binding sites were identified within the HIF-1 $\alpha$ oxygen dependent degradation domain (12,13). Additionally, pVHL, a negative regulator of HIF-1 $\alpha$ stabilization, associates directly with p53 by inhibiting Hdm2-mediated ubiquitinylation (14). The p53 protein is modified through multiple posttranslational events, including phosphorylation and acetylation. These modifications stabilize and activate p53. Activation of p53 induces several target genes such as Hdm2 known as an E3 ubiquitin ligase of p53 (13) and the four phosphatases Wip1, Mkp1, Pac1 and Dusp5 known as negative regulators of the MAPK signaling (15).

Recently, we described that mild hypoxia (5\% oxygen) stabilizes the transcription factor HIF- $1 \alpha$ and induces target gene expression in MCF-7 cells. TCDD clearly reduced the hypoxia-induced stabilization and activation of HIF-1 $\alpha$ in an AhR-dependent manner. We could not find an influence of hypoxia on TCDD-mediated activation of AhR signaling in MCF-7 cells (16).

In this study, we describe the inhibition of p53 signaling in TCDD-treated MCF-7 cells under hypoxic conditions. We refer to hypoxic conditions when the $\mathrm{O}_{2}$-concentrations in the culture medium is reduced to $5 \%$ and HIF-1 $\alpha$ was shown to be stabilized in MCF-7 cells (16). We detected a moderate induction of $\mathrm{Hdm} 2$ and ER $\alpha$ expression that negatively affected p53 activity. Inhibition of p53 caused a decrease of the phosphatase Dusp5 which resulted in increased ERK1/2 phosphorylation. This ERK1/2 phosphorylation resulted in increased $\mathrm{ER} \alpha$ transactivation and $\mathrm{Hdm} 2$ induction. In this way, we suggest a model for interaction of AhR/HIF- $1 \alpha /$ p53 signaling after exposure to TCDD under moderate hypoxic conditions that could explain detrimental effects of TCDD in breast tumorigenesis.

\section{Materials and methods}

Chemicals. The chemicals used were obtained from the following companies: 2,3,7,8-TCDD (>99\% pure, Amchro, Hattersheim, Germany); $\alpha$-naphthoflavone (ANF), dimethylsulfoxid (DMSO) and the inhibitor of the activated mitogenactivated protein kinase kinase (MAPKK) PD98059 were obtained from Sigma (Taufkirchen, Germany). TCDD, ANF and PD98059 were dissolved in DMSO.

Cell line, exposure and inhibitors. The ER-positive human breast cancer cell line MCF-7 was obtained from Deutsche Sammlung von Mikroorganismen und Zellkulturen (DSMZ, Braunschweig, Germany). MCF-7 cells express wild-type p53 protein (17). Culture of MCF-7 cells were described previously (16). Cells were plated and allowed to attach for $24 \mathrm{~h}$. For stimulation they were treated with $10 \mathrm{nM}$ TCDD in a humidified atmosphere with $20 \% \mathrm{O}_{2}, 5 \% \mathrm{CO}_{2}$ at $37^{\circ} \mathrm{C}$ (normoxic condition). For stimulation of hypoxic conditions, the culture medium was equilibrated for $6 \mathrm{~h}$ under hypoxic conditions with $5 \% \mathrm{O}_{2}$. The cells were sealed in a hypoxic chamber equilibrated with $5 \% \mathrm{O}_{2}, 5 \% \mathrm{CO}_{2}$ and $37^{\circ} \mathrm{C}$ and fed with the equilibrated medium. For double exposure (TCDD and hypoxia) the TCDD-treated cells were cultured under hypoxic conditions. The final concentration of $0.001 \%$ DMSO was used as vehicle control. For inhibition of the AhR with its specific inhibitor ANF $(10 \mu \mathrm{M})$ or inhibition of MAPKK (MEK-1/2) with its specific inhibitor PD98059 (50 $\mu \mathrm{M})$ MCF-7 cells were incubated for 4 and $1 \mathrm{~h}$ prior stimulation with TCDD and/or hypoxia, respectively.

RNA preparation and real-time RT-PCR. Isolation of total cellular RNA, synthesis of cDNA, real-time PCR amplification and analysis was described previously (16). The primers used were as follows: Hdm2 (NCBI, acc. NM_002392): forward 5'-GGTGGGAGTGATCAAAAGGA-3' and reverse 5'-ACA CAGAGCCAGGCTTTCAT-3'; Dusp5 (NCBI, acc. NM_004419): forward 5'-GGAGGCCTTCGATTACATCA-3' and reverse 5'-AGGGCTCAGTGTCTGCAAAT-3'; SOCS3 (NCBI, acc. NM_003955): forward 5'-GTGGCCACTCTTC AGCATCT-3' and reverse 5'-CTCTCCTGGTTGGCTTC TTG-3'; ribosomal 18S (NCBI, acc. X00686): forward 5'GTTGGTGGAGCGATTTGTCTGG-3' and reverse 5'-AGG GCAGGGACTTAATCAACGC-3'. Melting curves were generated for verification of the PCR-product. Additionally, gel electrophoresis was performed to prove the quality of the PCR product. Relative RNA amounts were determined with the Opticon II System software. $C_{\mathrm{t}}$ values for all genes analysed were determined six times, averaged, and normalized to values for the endogenous control $18 \mathrm{~S}$. The relative mRNA amounts were calculated by using the $\Delta \Delta$ ct method (16).

Immunoblotting. Western blots were performed with $50 \mu \mathrm{g}$ total protein of MCF-7 cells. Proteins were electroblotted from NuPAGE gels (NOVEX, Frankfurt-Hoechst, Germany) onto Hybond ECL membrane (Amersham, Freiburg, Germany). The membrane was blocked with $5 \%$ low-fat milk power in TBST for $1 \mathrm{~h}$ at RT. Blots were incubated with mouse monoclonal phospho-p42/p44 MAPK antibody (1:1000, Cell Signaling, Boston, MA), mouse monoclonal p42/p44 MAPK antibody (1:1000, Cell Signaling, Boston, MA), mouse monoclonal p53 antibody DO1 (1:1000, DakoCytomation, Denmark), rabbit polyclonal mdm2 antibody (1:200, Santa Cruz) and rabbit polyclonal Dusp5 antibody (1:1000, Biozol, Eching) in TBST with $5 \%$ low-fat milk powder at $4{ }^{\circ} \mathrm{C}$ overnight. Blots were washed 3 times and incubated for $1 \mathrm{~h}$ with the HRP-conjugated secondary antibody (anti-mouse $\mathrm{IgG}, 1: 10000$ dilution, or anti-rabbit $\mathrm{IgG}, 1: 10000$ dilution, Dianova, Hamburg, Germany). Immunodetection was accomplished using the ECL Western blotting detection reagents (Amersham) for chemiluminescent detection and the ECL Hyperfilm (Amersham). The blots were rinsed with 2\% SDS, $60 \mathrm{mM}$ Tris-HCl, pH 6.0-7.0, and $100 \mathrm{mM} \mathrm{B-mercapto-}$ ethanol at $50^{\circ} \mathrm{C}$ for $30 \mathrm{~min}$ and re-probed with mouse anti- $\beta$ actin (Sigma Aldrich).

Transient transfection methods. For reporter gene experiments MCF-7 $\left(5 \times 10^{4}\right.$ cells) were cotransfected with $1.5 \mu \mathrm{g}$ of pTalluc/ERE (18), $1.5 \mu \mathrm{g}$ of pTal-luc/p53 (Clontech, Heidelberg, Germany) or $1.5 \mu \mathrm{g}$ XRE-pTAL-Luc (16) and $0.08 \mu \mathrm{g}$ of pRLSV40 (Promega) and/or 100 ng Dusp5 siRNA (5'-CCCU 
A)

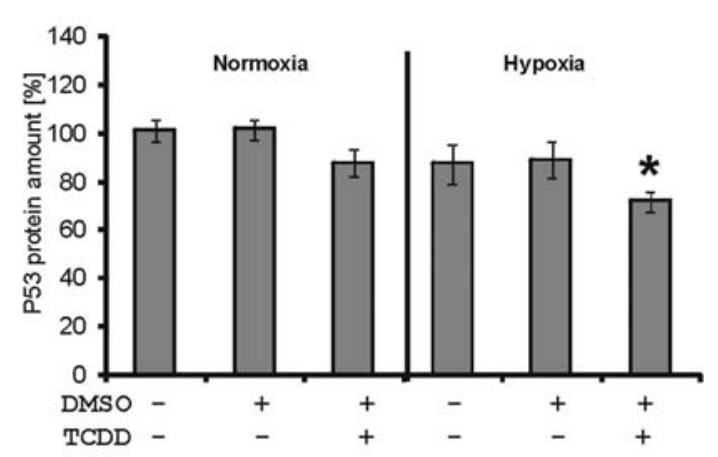

C)

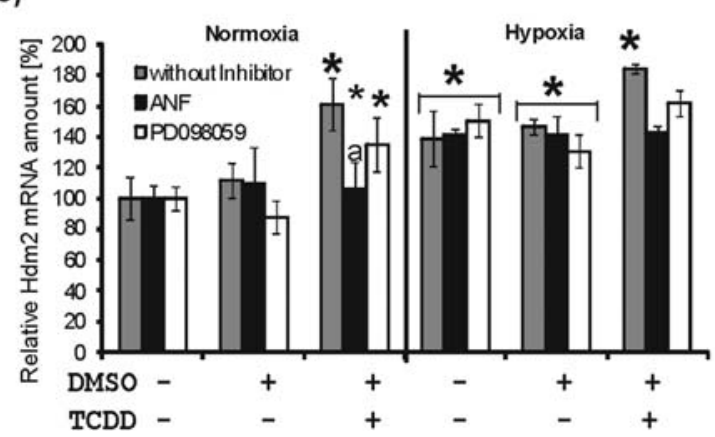

B)
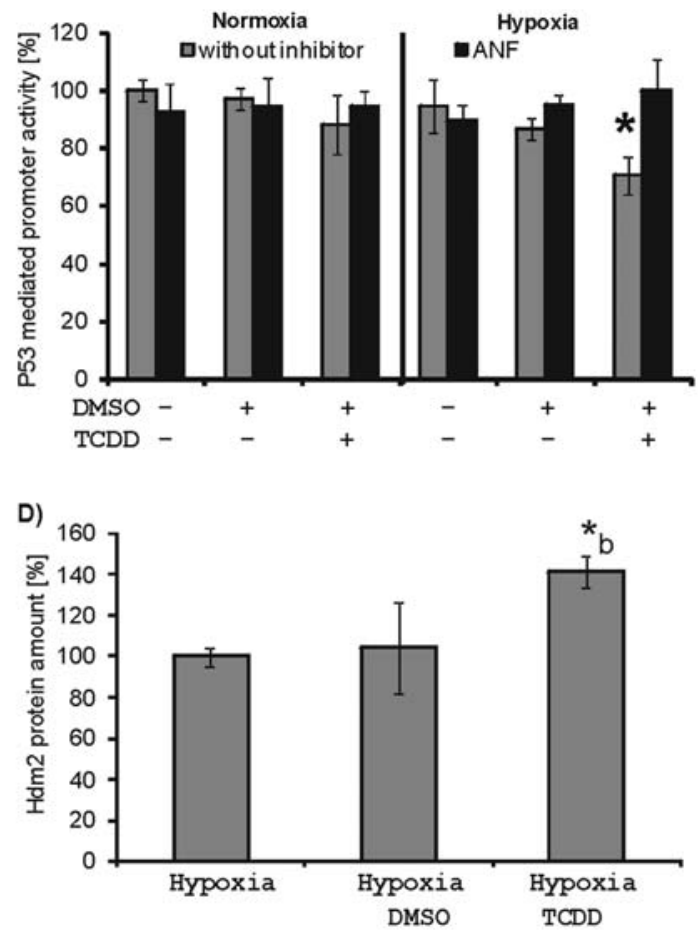

Figure 1. Regulation of p53 protein amount (A), p53 promoter activity (B), Hdm2 transcription (C) and Hdm2 protein expression (D) in MCF-7 cells. (A) p53 protein amount was quantified by Western blotting in cells exposed to $10 \mathrm{nM}$ TCDD under normoxia or hypoxia for $6 \mathrm{~h}$. A densitometrical analysis of the p53 protein band intensities in relation to $\beta$-actin was performed. The relative amount of p53 in percent of the non-treated control cells is shown. Data represent results from at least three separate experiments. (B) Cells were transiently transfected with a p53 reporter gene construct and incubated for 24 h. Firefly luciferase activity was normalized to those of renilla luciferase, providing an internal control. Results are expressed in percent of the untreated control. Data represent results from at least three separate experiments. (C) Relative Hdm2 mRNA amount was measured using quantitative RT-PCR. Data represent results from at least three separate experiments. (C) Hdm2 protein amount was quantified by Western blotting in cells after a 6-h exposure of hypoxia with or without $10 \mathrm{nM}$ TCDD. A densitometrical analysis of the $\mathrm{Hdm} 2$ protein band intensities in relation to $\beta$-actin was performed. The relative amount of Hdm 2 protein in percent of the non-treated control cells is shown. Data represent results from at least two separate experiments ( ${ }^{*} \mathrm{p}<0.05$ compared to non-treated and DMSOtreated normoxic control, ${ }^{*}$ a $\mathrm{p}<0.05$ compared to single exposure to TCDD; ${ }^{*} \mathrm{~b} \mathrm{p}<0.05$ compared to hypoxic control).

UCCUCUACCUUGGAA-3') or 100 ng non-specific siRNA (19), using Metafectene (Biontex laboratories GmBH, Echingen, Germany) according to the manufacturer's instructions. Six hours after transfection, media were changed and cells were stimulated as described above for $24 \mathrm{~h}$. Cells were lysed and luciferase activity was measured using the Dual luciferase kit (Promega) according to the manufacturer's instructions and the Sirius 2 luminometer (Berthold detection systems). Results were normalized to the renilla luciferase activity of the pRLSV40 vector.

Statistical analysis. The results were compared with ANOVA for all pairwise multiple comparisons and with the Student's t-test for single comparison to the non-treated control. Statistically significant differences were set at $\mathrm{p}<0.05$.

\section{Results}

Regulation of the tumor suppressor p53 in TCDD-treated MCF-7 cells under hypoxic conditions. We observed a reduction in $\mathrm{p} 53$ protein amount after simultaneous exposure to TCDD and hypoxia (down to $73 \%$, Fig. 1A) whereas single exposure showed no significant effect. The downregulation of p53 could be prevented by application of the
AhR-specific inhibitor ANF (data not shown). Next we studied if p53 down-regulation was caused by $\mathrm{Hdm} 2$ protein which can mark p53 for proteasomal degradation. Hdm2 mRNA amount was induced to $150 \%$ by TCDD, to $140 \%$ by hypoxia alone and to $180 \%$ by simultaneous exposure to TCDD and hypoxia (Fig. 1C). Compared to hypoxia alone the $\mathrm{Hdm} 2$ protein expression was increased to $140 \%$ after simultaneous exposure (Fig. 1D). Treatment with the AhR-specific inhibitor alpha-naphtoflavone (ANF) suppressed the TCDD-mediated increase of Hdm2 mRNA under normoxia and hypoxia. To test if Hdm2 mRNA induction was affected by phosphorylation through MAPKK, an inhibitor of MAPKK, PD98059, was applied. After double exposure this inhibitor down-regulated the Hdm2 mRNA amount, but not after a single exposure (Fig. 1C). To avoid discussion about effects of PD98059 on TCDD-mediated AhR activation (20), we measured induction of XRE promoter activity. PD98059 did not change TCDDmediated increase in XRE promoter activity (Fig. 2A).

As consequence of the down-regulation of $\mathrm{p} 53$ protein, the $\mathrm{p} 53$-mediated promoter activity was significantly reduced only in one group: the simultaneous exposure to TCDD and hypoxia (Fig. 1B). We investigated whether the expression of the p53 target genes Pac1, MKP1, and Dusp5 were downregulated as well. We did not find changes in the mRNA levels 
A)

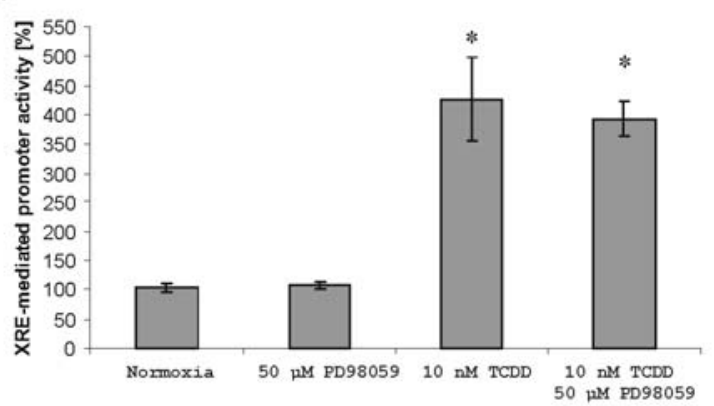

C)

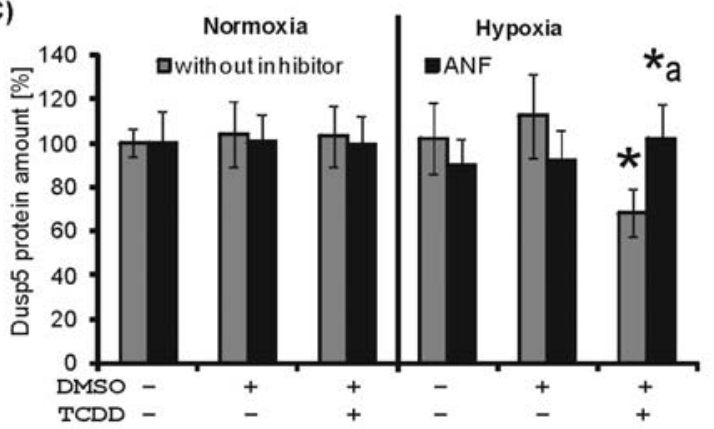

E)

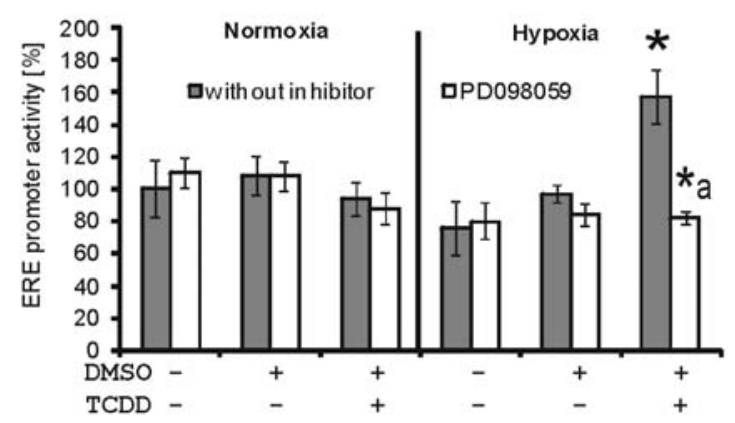

G)

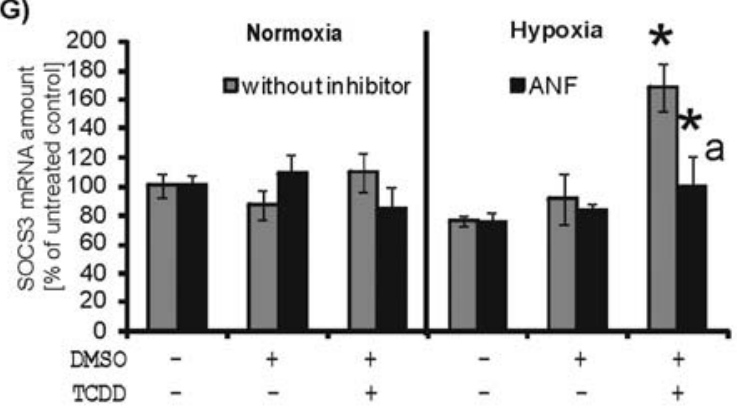

B)

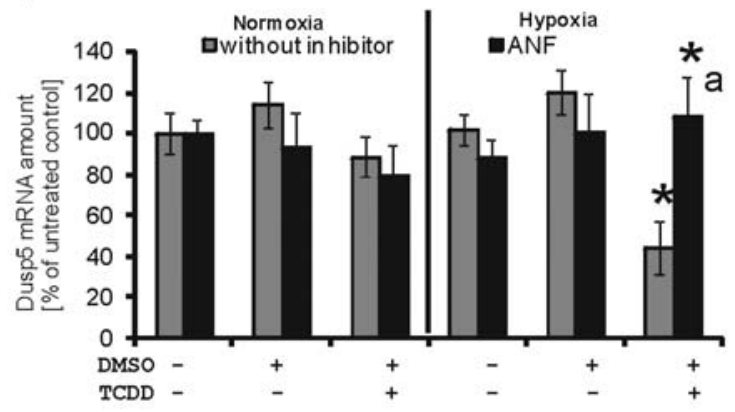

D)

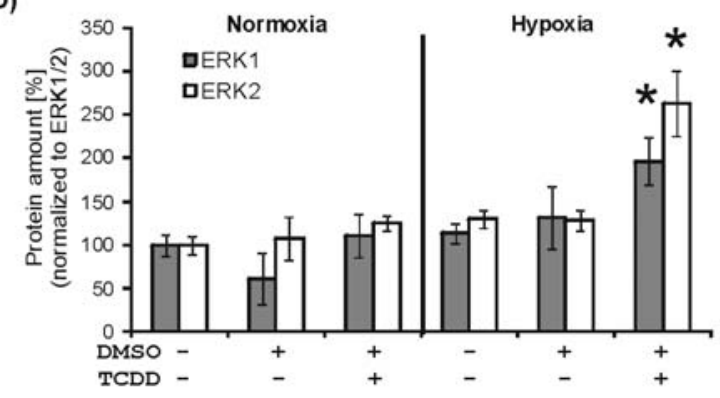

F)

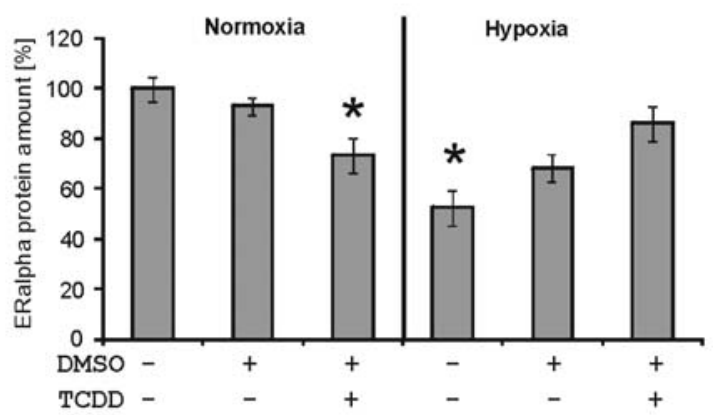

Figure 2. Regulation of XRE promoter activity (A), regulation of Dusp5 mRNA (B) and protein (C) expression, phosphorylation of ERK1/2 protein (D), activation of ERE mediated promoter activity (E), regulation of ER $\alpha$ protein $(\mathrm{F})$ and SOCS3 mRNA (G) amount in MCF-7 cells after exposure to TCDD and/or hypoxia. (A) Cells were transiently transfected with an XRE reporter gene construct, incubated for $24 \mathrm{~h}$ and treated with $10 \mathrm{nM}$ TCDD and/or $50 \mu \mathrm{M}$ PD98059. Firefly luciferase activity was normalized to those of renilla luciferase, providing an internal control. Results are expressed in percent of the untreated control. (B) Relative Dusp5 mRNA amounts were measured using quantitative RT-PCR. (C) The Dusp5 protein amount was quantified by Western blotting in cells exposed to $10 \mathrm{nM}$ TCDD under hypoxia or normoxia for $6 \mathrm{~h}$. A densitometrical analysis of the Dusp5 protein band intensities in relation to B-actin was performed. The relative amount of Dusp5 in percent of the non-treated control cells is shown. (D) ERK1/2 protein phosphorylation was quantified by Western blotting in cells exposed to $10 \mathrm{nM}$ TCDD under normoxia or hypoxia for $6 \mathrm{~h}$. A densitometrical analysis of the phospho-ERK1/2 protein bands intensity in relation to nonphospho-ERK1/2 protein was performed. The relative amount of phosphorylated ERK1/2 in percent of the non-treated control cells is shown. (E) Cells were transiently transfected with a ERE reporter gene construct and incubated for $24 \mathrm{~h}$. Firefly luciferase activity was normalized to those of renilla luciferase, providing an internal control. Results are expressed in percent of the untreated control. (F) ER $\alpha$ protein amount was quantified by Western blotting in cells exposed to $10 \mathrm{nM}$ TCDD under normoxia or hypoxia for $6 \mathrm{~h}$. A densitometrical analysis of the ER $\alpha$ protein band intensities in relation to $\beta$-actin was performed. The relative amount of ER $\alpha$ in percent of the non-treated control cells is shown. (G) Relative SOCS3 mRNA amounts were measured using quantitative RT-PCR. All data represent results from at least three separate experiments ( ${ }^{*}<0.05$ compared to non-treated and DMSO-treated normoxic control, ${ }^{*}$ a $\mathrm{p}<0.05$ compared to simultaneous exposure to TCDD and hypoxia).

of Pac1 and MKP1 (data not shown) in exposed MCF-7 cells, but detected a reduction of Dusp5 mRNA to 50\% following double exposure (Fig. 2B). Furthermore, a decrease of Dusp5 protein to $70 \%$ was found after treatment with TCDD under hypoxic conditions compared to MCF-7 cells equally treated but incubated with the AhR inhibitor ANF (Fig. 2C). 
A)

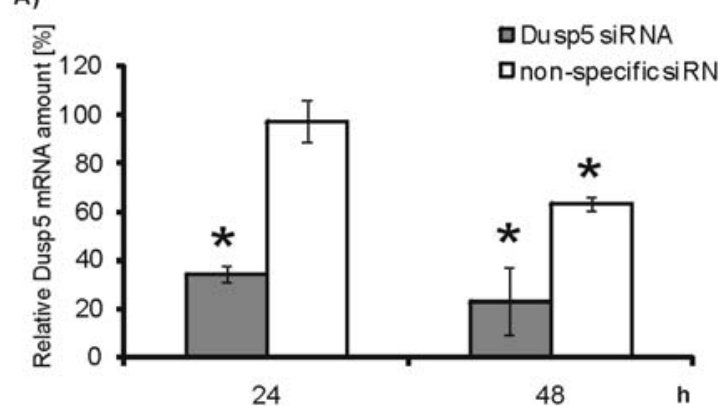

C)

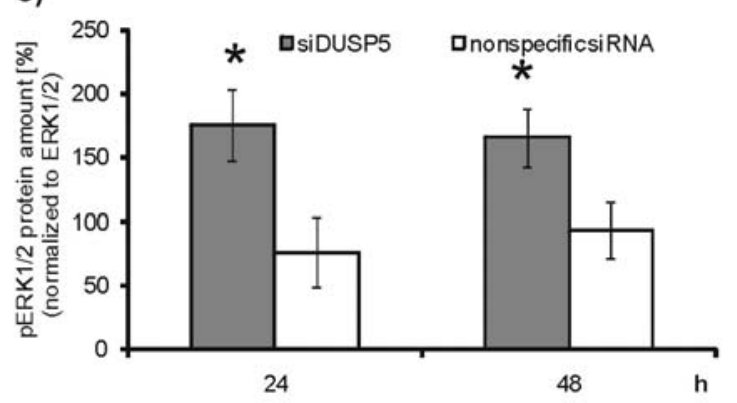

E)

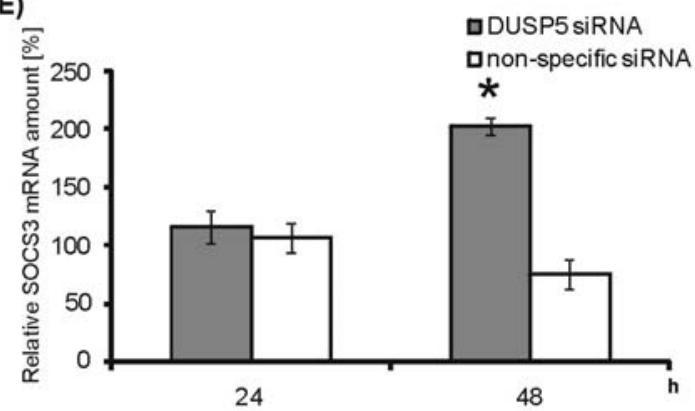

B)

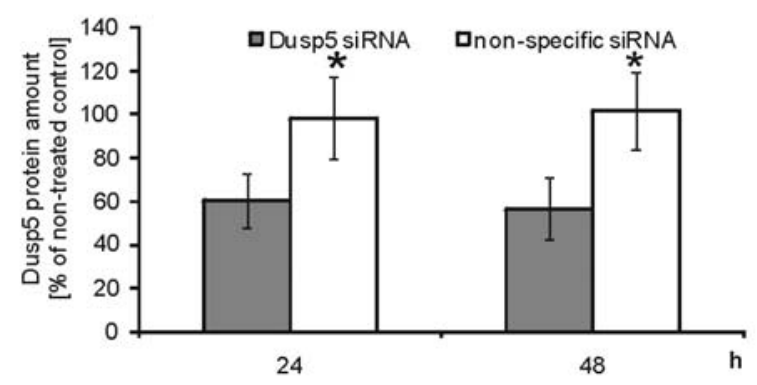

D)

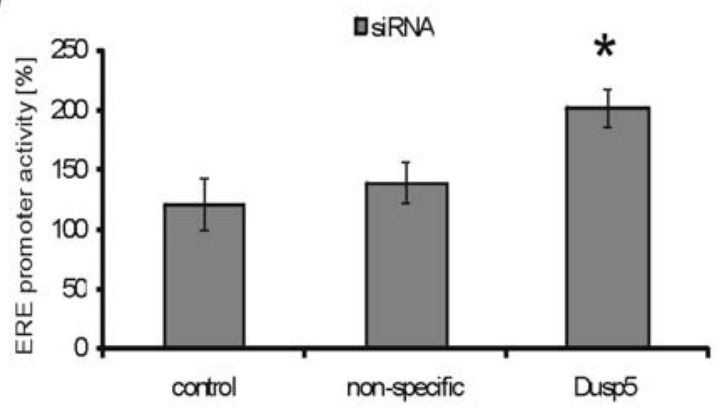

F)

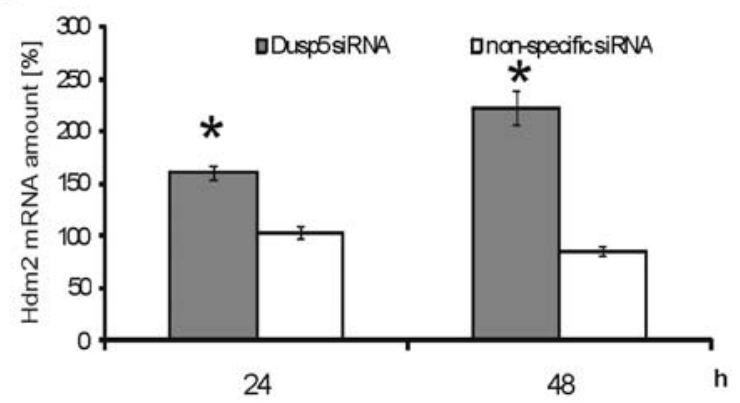

Figure 3. Regulation of Dusp5 mRNA (A) and protein expression (B), phosphorylation of ERK1/2 protein (C), activation of ERE mediated promoter activity (D) and regulation of SOCS3 (E) and Hdm2 (F) transcription in MCF-7 cells after Dusp5 silencing transcription. Cells were transiently transfected with a Dusp5 specific or non-specific siRNA and incubated for 24 and 48 h. (A) Relative Dusp5 mRNA amounts were measured using quantitative RT-PCR. (B) The Dusp5 protein amount was quantified by Western blotting. A densitometrical analysis of the Dusp5 protein band intensities in relation to $\beta$-actin was performed. The relative amount of Dusp5 in percent of the non-treated control cells is shown. (C) The ERK1/2 protein phosphorylation was quantified by Western blotting. A densitometrical analysis of the phospho-ERK1/2 protein bands intensity in relation to nonphospho-ERK1/2 protein was performed. The relative amount of phosphorylated ERK1/2 in percent of the non-treated control cells is shown. (D) Cells were transiently transfected with an ERE reporter gene construct in addition to a Dusp5 specific or non-specific siRNA and incubated for $24 \mathrm{~h}$. Firefly luciferase activity was normalized to those of renilla luciferase, providing an internal control. Results are expressed in percent of the untreated control. (E and F) Relative SOCS3 and Hdm2 mRNA amounts were measured using quantitative RT-PCR. All data represent results from at least three separate experiments ( $\mathrm{p}<0.05$ compared to non-treated normoxic control).

Phosphorylation of ERK and regulation of ERa protein and transcriptional activity. We investigated if down-regulation of the phosphatase Dusp5 showed an effect on phosphorylation of ERK1/2. Simultaneous exposure of TCDD and hypoxia increased the phosphorylation of ERK $1 / 2$ to $250 \%$ compared to the untreated normoxic control (Fig. 2D). Semi-quantitative analyses of phosphorylation of the two ERK proteins showed that the amount of phosphorylated ERK2 was higher than that of ERK1. ANF inhibited the increased phosphorylation of ERK1/2 (data not shown). To test the possible transactivation of ER $\alpha$ by phosphorylated ERK1/2 the EREmediated promoter activity was determined. The ERE promoter activity was increased to $170 \%$ after simultaneous exposure to TCDD and hypoxia (Fig. 2E). This increase was prevented by the MAPKK-inhibitor PD98059. The ER-dependent induction of ERE promoter activity was approved by using the inhibitor ICI 182780 (data not shown). In addition, ER $\alpha$ protein amount was quantified in exposed MCF-7 cells. The protein amount was reduced approximately 25 and $50 \%$, respectively, by TCDD and hypoxia compared to untreated normoxic control. Simultaneous exposure resulted in only $15 \%$ reduction of $\mathrm{ER} \alpha$ protein compared to the untreated normoxic control (Fig. 2F). The promoter of SOCS3, an ER target gene, has been previously described to contain the ERE sequence that we used in this study (21). SOCS3 transcription was increased to $160 \%$ only after simultaneous exposure to TCDD and hypoxia compared to equally treated cells but incubated with the AhR inhibitor ANF (Fig. 2G).

Inhibition of Dusp5 phosphorylates ERK1/2 and regulates ER-mediated promoter activity and target gene expression. The inhibition of p53 signaling on ER $\alpha$ signaling via Dusp5 downregulation and ERK1/2 phosphorylation was studied. Dusp5 siRNA reduced the Dusp5 mRNA and protein levels to 40 and $60 \%$, respectively (Fig. 3A and B). The nonsilencing siRNA did not affect the Dusp5 protein amount 


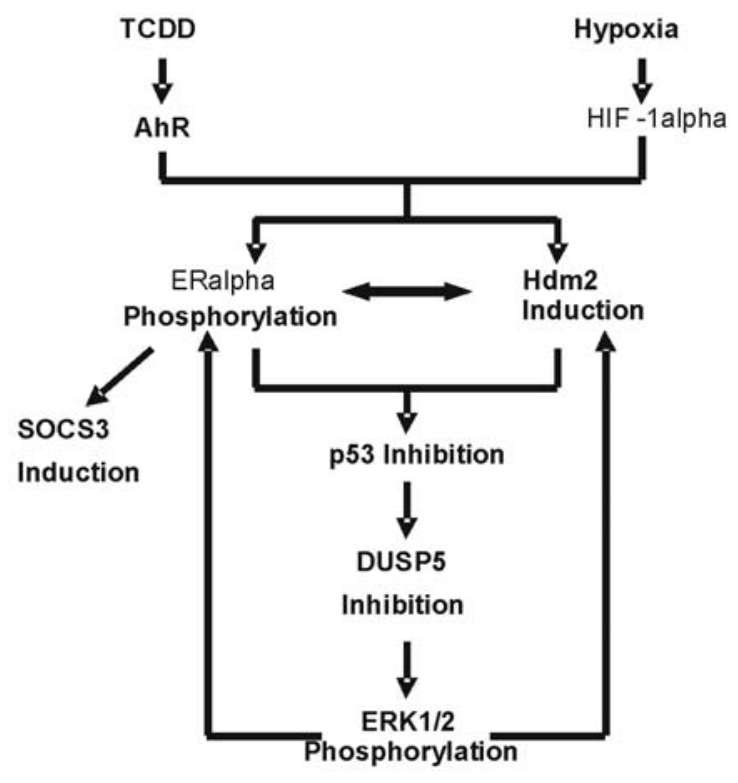

Figure 4. Signal transduction pathway promoting inhibition of p53 signaling and transactivation of ER $\alpha$ signaling. The combination of inhibition of functional p53 protein and induction of ER $\alpha$ signaling provides a new model to explain TCDD toxicity and TCDD-induced network affecting breast tumor progression in MCF-7 cells under hypoxic, physiologic conditions. In addition to the observed effects in this study, it was shown that the ERK $1 / 2$ phosphorylation can also result in an autoregulatory feedback loop that controls $\mathrm{Hdm} 2$ protein synthesis (17).

after 24 and 48 h (Fig. 3A). The reduction in Dusp5 expression resulted in an increased phosphorylation of ERK1/2 to $\sim 180 \%$ after 24 and $48 \mathrm{~h}$, whereas the non-specific siRNA did not affect ERK1/2 phosphorylation (Fig. 3C). Increased ERK1/2 phosphorylation was associated with an increase in ERE-mediated promoter activity to $200 \%$ (Fig. 3D). Finally, mRNA expression of the ER $\alpha$ target genes SOCS3 and Hdm2 was significantly increased to 200 and $220 \%$ after $48 \mathrm{~h}$ of Dusp5 silencing (Fig. 3E and F).

\section{Discussion}

In this study, we used the estrogen-responsive human breast cancer cell line MCF-7 to investigate the consequences of activation of both, AhR and HIF-1 $\alpha$ signaling. Recently, we studied the interference between the AhR and HIF- $1 \alpha$ signaling in MCF-7 cells (16). There we clearly showed TCDD-mediated and AhR-dependent reduction in activation of HIF-1 $\alpha$ under hypoxic (5\% oxygen) conditions. The used oxygen concentration in this study correlated with those reported in normal breast tissue and breast carcinoma (stage T1B to T4) (9). On the other hand hypoxia did not change TCDD-mediated activation of AhR signaling in MCF-7 cells. Lower oxygen concentrations (1\%) were shown to inhibit the AhR signaling in human breast cancer cells (22). Several other studies also described that the activation of AhR pathway inhibits activation of HIF- $1 \alpha$ pathway and vice versa in rats (23), mice (23) and multiple cell lines (24). However, the consequences of activation of both AhR and HIF-1 $\alpha$ signaling are still poorly understood. In this study, we show for the first time the inhibition of p53 and subsequent activation of the $\mathrm{ER} \alpha$ signaling after simultaneous activation of both pathways.
Simultaneous activation of AhR and HIF-1 $\alpha$ signaling caused via direct activation of the ER $\alpha$ and the transcriptional regulation of $\mathrm{Hdm} 2$ a moderate inhibition of p53 transcriptional activity and protein expression in MCF-7 cells. In contrast, single exposure to TCDD or hypoxia did not cause p53 inhibition due to loss of $\mathrm{ER} \alpha$ activation. Multiple mechanisms are known to regulate p53 protein expression. p53 stability and degradation is regulated for example via the E3 ubiquitin ligase $\mathrm{Hdm} 2$ (25) and interference with the ER $\alpha$ signaling (26). We observed an up-regulation of $\mathrm{Hdm} 2$ transcription and protein expression after treatment with TCDD and hypoxia (Fig. 1C and D). This is in agreement with the finding that a single exposure to TCDD increased $\mathrm{mdm} 2$ protein amount and subsequent degradation of p53 in mice (27). Hdm2 was shown to interact with the N-terminus of $\mathrm{p} 53$, inhibit p53 transcriptional activity and to promote its proteasomal degradation (25). Furthermore, an interaction between $\mathrm{HIF}-1 \alpha$ and $\mathrm{p} 53$ was proposed to function indirectly via $\mathrm{Hdm} 2$ (28). On the other hand, $\mathrm{Hdm} 2$ can be transcriptionally upregulated by ER $\alpha$ signaling $(29,30)$. In breast cancer cells, increased expression of ER $\alpha$ led to elevated levels of mdm2 (31) and over-expression of $\mathrm{mdm} 2$ enhanced $\mathrm{ER} \alpha$ function (32). To investigate whether ER $\alpha$ signaling was altered under the influence of TCDD and hypoxia we examined ER $\alpha$ protein expression and ER $\alpha$ transcriptional activity in MCF-7 cells after exposure to TCDD and/or hypoxia. After single exposure to TCDD or hypoxia we observed down-regulation in ER $\alpha$ protein expression (Fig. 2F). An increased proteasomal degradation of the ER $\alpha$ after AhR or HIF-1 $\alpha$ activation was described previously $(3,33)$. However, we showed that this ER $\alpha$ down-regulation was inhibited and the ER $\alpha$ transcriptional activity was increased after simultaneous exposure to TCDD and hypoxia. Therefore, we propose that the simultaneous activation of AhR and HIF-1 $\alpha$ overcomes the induction of proteasomal degradation of ER $\alpha$. Several studies have described an inhibitory effect of AhR activation on ER $\alpha$ signaling (3). However, TCDD-activated AhR/ARNT heterodimers were shown to directly associate with ER $\alpha$ resulting in ER $\alpha$ activation in the absence of E2 (34). HIF-1 $\alpha$ was described to directly associate with ER $\alpha$ causing its activation $(35,36)$. In this study, we observed an ER $\alpha$ transcriptional activation exclusively under simultaneous activation of $\mathrm{AhR}$ and HIF-1 $\alpha$ pathways in MCF-7 indicating a stimulative crosstalk of both pathways causing an estrogenic effect.

We investigated whether the down-regulation of p53 transcriptional activity was linked to increased ER $\alpha$ activation. Single exposure to TCDD or hypoxia showed no significant effect on p53 transcriptional activity or target gene expression. Since ER $\alpha$ was shown to directly bind to p53 and inhibit p53 transcriptional activity (26) we suppose that the decreased expression of ER $\alpha$ after a single exposure prevents the inhibition of p53 activation.

After simultaneous exposure to TCDD and hypoxia the decrease in 553 protein resulted in a decreased transcriptional activity and target gene expression (Figs. 1, 2B and C). We analysed expression of the p53 target genes and phosphatases, Pac1, MKP1 and Dusp5. The Dusp5 expression was significantly increased after simultaneous exposure whereas the relative mRNA amount of Pac1 and MKP1 after exposure to TCDD and/or hypoxia was not changed (data not shown) 
indicating Dusp5 to be the prime p53-target in MCF-7 cells. The transcriptional regulation of Dusp5 via p53 binding sites in the promoter region has been described previously (37). It was also shown that p53-mediated induction of different phosphatases, such as Pac1, MKP1 and Dusp5, by transcriptional regulation inhibited MAPK signaling (15). A functional study showed that Dusp5 can preferentially dephosphorylate extracellular signal-regulated kinases (ERKs) (37). Mandl et al (38) described that Dusp5 binds specifically and directly to ERK2 via a kinase interacting motif inactivating ERK2. In the present study we were also able to show that downregulation of Dusp5 resulted in an increased phosphorylation of ERK2 (Fig. 3C).

To demonstrate the direct influence of Dusp5-mediated increase in ERK-phosphorylation on ER $\alpha$ signaling, we silenced the Dusp5 mRNA expression by RNA interference. We showed that silencing of Dusp5 resulted in phosphorylation of ERK1/2 comparable to the effects observed after simultaneous exposure to TCDD and hypoxia. Both simultaneous exposure and Dusp5-silencing lead to an increase in ER $\alpha$ transcriptional activity (Figs. 2D and 3D). Activation of ER $\alpha$ via phosphorylation at multiple sites (S104, S106, S118, S167, S236, Y537) by various kinases has been reported (1). Phosphorylation of the human ER $\alpha$ at S118 is mediated by MAPK including ERK1/2 in response to different stimuli (39). We demonstrate here that inhibition of the specific MAPKK for ERK1/2 with PD98059 (40) prevented ER $\alpha$ mediated transcriptional induction after simultaneous exposure to TCDD and hypoxia. Dephosphorylation of ER $\alpha$ at site S118 by the phosphatase Dusp22 has been shown (41) but not yet for Dusp5. We suggest that the inhibition of the p53 target gene Dusp5 abrogates dephosphorylation of ER $\alpha$ and that phosphorylation of ER $\alpha$ by ERK1/2 increases ER $\alpha$-mediated transcriptional activity (Fig. 4).

Thus, the negative regulation of the p53 pathway after simultaneous exposure to TCDD and hypoxia caused induction of ER $\alpha$ target gene expression (Fig. 4) and Dusp5 downregulation played an essential role in this ER activation. Both, simultaneous exposure to TCDD and hypoxia and Dusp5-silencing resulted in the induction of the ER target genes SOCS3 (21). SOCS3 is a negative regulator of cytokineinduced signaling (42). The induction of SOCS3 by TCDD and hypoxia may provide a new mechanism for modulation of cytokines that are involved in TCDD mediated toxicity and/or metabolic disorders. The increase in Hdm2 mRNA expression after simultaneous exposure to TCDD and hypoxia was not significantly affect by the upstream inhibitor of ERK1/2, PD98059, suggesting that TCDD and hypoxia are acting upstream from the MAPKK/ERK pathway. Dusp5silencing results in an increase in $\mathrm{Hdm} 2$ expression pointing to an ER $\alpha$-mediated strengthening of the initial Hdm2 expression $(29,30)$ after exposure to TCDD and hypoxia.

The main role for p53 is its function as key player in the inhibition of tumor development. p53 can induce a number of different responses, ranging from the induction of cell cycle arrest, cell death, DNA repair to the control of mitochondrial respiration (13). The estrogenic responses are relevant for tumorigenesis, invasion, and metastasis (43). Therefore, the combination of inhibition of functional p53 protein and induction of $\mathrm{ER} \alpha$ signaling (Fig. 4) could serve as a model for the operational sequence of TCDD effects to prevent cell death and promote breast tumor progression under hypoxic conditions.

\section{Acknowledgments}

This work was supported by DFG GK 416/3 and the Wilhelm Roux Program of the Martin Luther University Faculty of Medicine. We would like to thank Drs A. Levine and G. Bond for critical reading of the manuscript. The authors thank Mr. René Keil for helping to establish the RNA interference experiments. We thank Mr. Thomas Greither for his help with the Hdm2-Western hybridisation.

\section{References}

1. Pearce ST and Jordan VC: The biological role of estrogen receptors alpha and beta in cancer. Crit Rev Oncol Hematol 50: 3-22, 2004.

2. Matthews $\mathbf{J}$ and Gustafsson JA: Estrogen receptor and aryl hydrocarbon receptor signaling pathways. Nucl Recept Signal 4: e016, 2006.

3. Wormke M, Stoner M, Saville B, et al: The aryl hydrocarbon receptor mediates degradation of estrogen receptor alpha through activation of proteasomes. Mol Cell Biol 23: 1843-1855, 2003.

4. Denison MS and Nagy SR: Activation of the aryl hydrocarbon receptor by structurally diverse exogenous and endogenous chemicals. Annu Rev Pharmacol Toxicol 43: 309-334, 2003.

5. IARC: IARC Working Group on the Evaluation of Carcinogenic Risks to Humans: Polychlorinated Dibenzo-Para-Dioxins and Polychlorinated Dibenzofurans. Lyon, France, 4-11 February 1997. IARC Monogr Eval Carcinog Risks Hum 69: 1-631, 1997.

6. Abraham K, Knoll A, Ende M, Papke O and Helge H: Intake, fecal excretion, and body burden of polychlorinated dibenzo-pdioxins and dibenzofurans in breast-fed and formula-fed infants. Pediatr Res 40: 671-679, 1996.

7. Warner M, Eskenazi B, Mocarelli P, et al: Serum dioxin concentrations and breast cancer risk in the Seveso Women's Health Study. Environ Health Perspect 110: 625-628, 2002.

8. Kewley RJ, Whitelaw ML and Chapman-Smith A: The mammalian basic helix-loop-helix/PAS family of transcriptional regulators. Int J Biochem Cell Biol 36: 189-204, 2004.

9. Vaupel P, Briest S and Hockel M: Hypoxia in breast cancer: pathogenesis, characterization and biological/therapeutic implications. Wien Med Wochenschr 152: 334-342, 2002.

10. Schrenk D: Impact of dioxin-type induction of drug-metabolizing enzymes on the metabolism of endo- and xenobiotics. Biochem Pharmacol 55: 1155-1162, 1998.

11. Wenger RH: Cellular adaptation to hypoxia: $\mathrm{O}_{2}$-sensing protein hydroxylases, hypoxia-inducible transcription factors, and $\mathrm{O}_{2}$ regulated gene expression. FASEB J 16: 1151-1162, 2002.

12. Fels DR and Koumenis C: HIF-1alpha and p53: the ODD couple? Trends Biochem Sci 30: 426-429, 2005.

13. Horn HF and Vousden KH: Coping with stress: multiple ways to activate p53. Oncogene 26: 1306-1316, 2007.

14. Roe JS and Youn HD: The positive regulation of p53 by the tumor suppressor VHL. Cell Cycle 5: 2054-2056, 2006.

15. Wu GS: The functional interactions between the p53 and MAPK signaling pathways. Cancer Biol Ther 3: 156-161, 2004.

16. Seifert A, Katschinski DM, Tonack S, Fischer B and Navarrete Santos A: Significance of prolyl hydroxylase 2 in the interference of aryl hydrocarbon receptor and hypoxia-Inducible factor-1alpha signaling. Chem Res Toxicol 21: 341-348, 2008.

17. Phelps M, Phillips A, Darley $M$ and Blaydes JP: MEK-ERK signaling controls $\mathrm{Hdm} 2$ oncoprotein expression by regulating hdm 2 mRNA export to the cytoplasm. J Biol Chem 280: 16651-16658, 2005.

18. Hombach-Klonisch S, Pocar P, Kauffold J and Klonisch T: Dioxin exerts anti-estrogenic actions in a novel dioxin-responsive telomerase-immortalized epithelial cell line of the oorcine oviduct (TERT-OPEC). Toxicol Sci 90: 519-528, 2006.

19. Kim DH, Behlke MA, Rose SD, Chang MS, Choi S and Rossi JJ: Synthetic dsRNA Dicer substrates enhance RNAi potency and efficacy. Nat Biotechnol 23: 222-226, 2005. 
20. Reiners JJ Jr, Lee JY, Clift RE, Dudley DT and Myrand SP: PD98059 is an equipotent antagonist of the aryl hydrocarbon receptor and inhibitor of mitogen-activated protein kinase kinase. Mol Pharmacol 53: 438-445, 1998.

21. Matthews J, Almlof T, Kietz S, Leers J and Gustafsson JA: Estrogen receptor-alpha regulates SOCS-3 expression in human breast cancer cells. Biochem Biophys Res Commun 335: 168-174, 2005.

22. Khan S, Liu S, Stoner M and Safe S: Cobaltous chloride and hypoxia inhibit aryl hydrocarbon receptor-mediated responses in breast cancer cells. Toxicol Appl Pharmacol 223: 28-38, 2007.

23. Pollenz RS, Davarinos NA and Shearer TP: Analysis of aryl hydrocarbon receptor-mediated signaling during physiological hypoxia reveals lack of competition for the aryl hydrocarbon nuclear translocator transcription factor. Mol Pharmacol 56: $1127-1137,1999$

24. Gradin K, McGuire J, Wenger RH, et al: Functional interference between hypoxia and dioxin signal transduction pathways: competition for recruitment of the Arnt transcription factor. Mol Cell Biol 16: 5221-5231, 1996.

25. Ryan KM, Phillips AC and Vousden KH: Regulation and function of the p53 tumor suppressor protein. Curr Opin Cell Biol 13: 332-337, 2001.

26. Sayeed A, Konduri SD, Liu W, Bansal S, Li F and Das GM: Estrogen receptor alpha inhibits p53-mediated transcriptional repression: implications for the regulation of apoptosis. Cancer Res 67: 7746-7755, 2007.

27. Paajarvi G, Viluksela M, Pohjanvirta R, Stenius U and Hogberg J: TCDD activates Mdm2 and attenuates the p53 response to DNA damaging agents. Carcinogenesis 26: 201-208, 2005.

28. Chen $\mathrm{D}$, $\mathrm{Li} \mathrm{M}$, Luo J and $\mathrm{Gu} \mathrm{W}$ : Direct interactions between HIF-1 alpha and Mdm2 modulate p53 function. J Biol Chem 278: 13595-13598, 2003.

29. Bond GL, Hu W, Bond EE, et al: A single nucleotide polymorphism in the MDM2 promoter attenuates the p53 tumor suppressor pathway and accelerates tumor formation in humans. Cell 119: 591-602, 2004.

30. Bond GL, Hirshfield KM, Kirchhoff T, et al: MDM2 SNP309 accelerates tumor formation in a gender-specific and hormonedependent manner. Cancer Res 66: 5104-5110, 2006.

31. Liu G, Schwartz JA and Brooks SC: Estrogen receptor protects p53 from deactivation by human double minute-2. Cancer Res 60: $1810-1814,2000$.
32. Saji S, Okumura N, Eguchi H, et al: MDM2 enhances the function of estrogen receptor alpha in human breast cancer cells. Biochem Biophys Res Commun 281: 259-265, 2001.

33. Stoner M, Saville B, Wormke M, Dean D, Burghardt R and Safe S: Hypoxia induces proteasome-dependent degradation of estrogen receptor alpha in ZR-75 breast cancer cells. Mol Endocrinol 16: 2231-2242, 2002.

34. Ohtake F, Takeyama K, Matsumoto T, et al: Modulation of oestrogen receptor signalling by association with the activated dioxin receptor. Nature 423: 545-550, 2003.

35. Cho J, Kim D, Lee S and Lee Y: Cobalt chloride-induced estrogen receptor alpha down-regulation involves hypoxia-inducible factor-1alpha in MCF-7 human breast cancer cells. Mol Endocrinol 19: 1191-1199, 2005.

36 Cho J, Bahn JJ, Park M, Ahn W and Lee YJ: Hypoxic activation of unoccupied estrogen-receptor-alpha is mediated by hypoxiainducible factor-1 alpha. J Steroid Biochem Mol Biol 100: 18-23, 2006.

37. Ueda K, Arakawa H and Nakamura Y: Dual-specificity phosphatase 5 (DUSP5) as a direct transcriptional target of tumor suppressor p53. Oncogene 22: 5586-5591, 2003.

38. Mandl M, Slack DN and Keyse SM: Specific inactivation and nuclear anchoring of extracellular signal-regulated kinase 2 by the inducible dual-specificity protein phosphatase DUSP5. Mol Cell Biol 25: 1830-1845, 2005.

39. Likhite VS, Stossi F, Kim K, Katzenellenbogen BS and Katzenellenbogen JA: Kinase-specific phosphorylation of the estrogen receptor changes receptor interactions with ligand, DNA, and coregulators associated with alterations in estrogen and tamoxifen activity. Mol Endocrinol 20: 3120-3132, 2006.

40. Watts SW: Serotonin activates the mitogen-activated protein kinase pathway in vascular smooth muscle: use of the mitogenactivated protein kinase kinase inhibitor PD098059. J Pharmacol Exp Ther 279: 1541-1550, 1996.

41. Sekine Y, Ikeda O, Hayakawa Y, et al: DUSP22/LMW-DSP2 regulates estrogen receptor-alpha-mediated signaling through dephosphorylation of Ser-118. Oncogene 26: 6038-6049, 2007.

42. Croker BA, Krebs DL, Zhang JG, et al: SOCS3 negatively regulates IL-6 signaling in vivo. Nat Immunol 4: 540-545, 2003.

43. DePasquale JA: Rearrangement of the F-actin cytoskeleton in estradiol-treated MCF-7 breast carcinoma cells. Histochem Cell Biol 112: 341-350, 1999. 
